\title{
Parasitic Plants Striga and Phelipanche Dependent upon Exogenous Strigolactones for Germination Have Retained Genes for Strigolactone Biosynthesis
}

\author{
Malay Das ${ }^{1,2}$, Monica Fernández-Aparicio1,3, Zhenzhen Yang4, Kan Huang5, \\ Norman J. Wickett4,6, Shannon Alford ${ }^{1}$, Eric K. Wafula ${ }^{4}$, Claude dePamphilis ${ }^{4}$, \\ Harro Bouwmeester ${ }^{7}$, Michael P. Timko5 ${ }^{5}$, John I. Yoder ${ }^{8}$, James H. Westwood ${ }^{1}$ \\ ${ }^{1}$ Department of Plant Pathology, Physiology and Weed Science, Virginia Tech, Blacksburg, VA, USA \\ ${ }^{2}$ Department of Biological Sciences, Presidency University, Kolkata, India \\ ${ }^{3}$ Institute for Sustainable Agriculture, Department of Plant Breeding, Spanish National Research Council, \\ Córdoba, Spain \\ ${ }^{4}$ Department of Biology, Institute of Molecular Evolutionary Genetics, Pennsylvania State University, University \\ Park, PA, USA \\ ${ }^{5}$ Department of Biology, University of Virginia, Charlottesville, VA, USA \\ ${ }^{6}$ Chicago Botanic Garden, Glencoe, IL, USA \\ ${ }^{7}$ Laboratory of Plant Physiology, Wageningen University, Wageningen, Netherlands \\ ${ }^{8}$ Department of Plant Sciences, University of California, Davis, Davis, CA, USA \\ Email: westwood@vt.edu
}

Received 27 March 2015; accepted 15 May 2015; published 18 May 2015

Copyright (C) 2015 by authors and Scientific Research Publishing Inc.

This work is licensed under the Creative Commons Attribution International License (CC BY).

http://creativecommons.org/licenses/by/4.0/

c) (i) Open Access

\section{Abstract}

Strigolactones are plant hormones with multiple functions, including regulating various aspects of plant architecture such as shoot branching, facilitating the colonization of plant roots by arbuscular mycorrhizal fungi, and acting as seed germination stimulants for certain parasitic plants of the family Orobanchaceae. The obligate parasitic species Phelipanche aegyptiaca and Striga hermonthica require strigolactones for germination, while the facultative parasite Triphysaria versicolor does not. It has been hypothesized that $P$. aegyptiaca and $S$. hermonthica would have undergone evolutionary loss of strigolactone biosynthesis as a part of their mechanism to enable specific detection of exogenous strigolactones. We analyzed the transcriptomes of $P$. aegyptiaca, $S$. hermonthica and $T$. versicolor and identified genes known to act in strigolactone synthesis $(D 27, C C D 7$, CCD8, and MAX1), perception (MAX2 and D14) and transport (PDR12). These genes were then analyzed to assess likelihood of function. Transcripts of all strigolactone-related genes were found

How to cite this paper: Das, M., Fernández-Aparicio, M., Yang, Z.Z., Huang, K., Wickett, N.J., Alford, S., Wafula, E.K., dePamphilis, C., Bouwmeester, H., Timko, M.P., Yoder, J.I. and Westwood, J.H. (2015) Parasitic Plants Striga and Phelipanche Dependent upon Exogenous Strigolactones for Germination Have Retained Genes for Strigolactone Biosynthesis. American Journal of Plant Sciences, 6, 1151-1166. http://dx.doi.org/10.4236/ajps.2015.68120 
in $P$. aegyptiaca and $S$. hermonthica, and evidence points to their encoding functional proteins. Gene open reading frames were consistent with homologs from Arabidopsis and other strigolactone-producing plants, and all genes were expressed in parasite tissues. In general, the genes related to strigolactone synthesis and perception appeared to be evolving under codon-based selective constraints in strigolactone-dependent species. Bioassays of $S$. hermonthica root extracts indicated the presence of strigolactone class stimulants on germination of $P$. aegyptiaca seeds. Taken together, these results indicate that Phelipanche aegyptiaca and $S$. hermonthica have retained functional genes involved in strigolactone biosynthesis, suggesting that the parasites use both endogenous and exogenous strigolactones and have mechanisms to differentiate the two.

\section{Keywords}

\section{Broomrape, Phelipanche, Striga, Strigolactone, Triphysaria, Witchweed}

\section{Introduction}

Parasitic plants of the genera Striga, Orobanche and Phelipanche (Orobanchaceae) have an absolute requirement for a host, and have evolved a mechanism by which seeds germinate specifically in response to the presence of a nearby host root. The parasite seeds are able to detect host roots by the presence of strigolactone (SL) compounds in root exudates [1] [2]. Although other compounds can act as germination signals, the SLs such as strigol, sorgolactone, and orobanchol have received most research attention because their production by host roots is well correlated with germination stimulant activity [3] [4].

Recent discoveries have provided both an ecological and developmental rationale for plants to produce SLs by showing that SLs are important signaling molecules in the rhizosphere that induce branching in arbuscular mycorrhizal (AM) fungi [5] and that they have characteristics of a plant hormone that contribute to regulation of shoot branching and other aspects of plant architecture (Extensively reviewed in recent literature, including [6] [7]-[10]). The origin of AM fungi symbiosis and shoot branching is ancient [11], and there is evidence that all angiosperms and even lower plants such as mosses and liverworts produce SLs [12]-[14]. However, the requirement of Orobanche, Phelipanche and Striga for exogenous SLs raises questions about how these species have evolved to respond to exogenous SLs and whether this trait could involve a loss in SL biosynthetic ability [15].

SLs are apocarotenoid compounds synthesized from $\beta$-carotene via a pathway that has been determined based on biosynthetic mutants of rice, pea, and Arabidopsis [16]. The first step in the pathway is the conversion of all-trans- $\beta$-carotene to 9-cis- $\beta$-carotene by the $\beta$-carotene isomerase D27 [17] [18]. Two Carotenoid Cleavage Dioxygenases (CCDs) then work sequentially to convert 9-cis- $\beta$-carotene into a C27 aldehyde (performed by CCD7) and then into carlactone (by CCD8) [18]. Both CCD7 and CCD8 are known to be essential for the production of SLs and the germination stimulant [19]-[22]. A cytochrome P450 dioxygenase is thought to act on carlactone to produce a SL, and while this enzyme is best known from Arabidopsis as MAX1, paralogs have been identified from several other species, suggesting that diversity in enzymes at this step may contribute to the variation in SL structures [23] [24].

The mechanism by which SL perception is transmitted as a germination signal is not understood, but branching regulation involves SL binding to D14 (DAD2 in Petunia hybrida), a member of the $\alpha / \beta$-hydrolase superfamily [25]-[27], which interacts with the F-box protein MAX2 [28] and leads to degradation of a transcriptional repressor. Similar systems function in auxin and jasmonic acid signaling [29]. A homolog of D14, termed KAI2 (karrikin insensitive), has been proposed to act like D14 in interacting with MAX2, but is involved in regulating seed germination in response to karrikin, a compound that is derived from smoke [30]. In addition to synthesis and signaling, SL activity may be influenced by transport. An ATP binding cassette transporter (Arabidopsis PDR12; PetuniaPDR1) has been identified as the cellular SL exporter that accounts for the exudation of SLs into the soil [31].

Parasitic plant use of the host SL signaling system provides an elegant example of how signals can be modified to serve an alternative function. Because SL-mediated regulation of branching is an ancient mechanism in angiosperms [13] [23] [32], autotrophic ancestors of parasitic plants are certain to have had this signaling path- 
way. The Orobanchaceae parasitic lineage has adapted this pathway for host detection by somehow modifying SL signaling during the crucial seed germination stage. One simple and direct means to this end was proposed to occur through the evolutionary loss of SL biosynthesis ability in parasitic species [15]. Under this scenario, parasite seeds would germinate only after detecting exogenous SLs produced by host roots, yet later in development the attached parasite could obtain SLs from the host through direct xylem connections [33].

The objectives of this research were to survey the key SL synthesis- and perception-related genes in Phelipanche aegyptiaca (syn. Orobanche aegyptiaca) and Striga hermonthica in order to discern whether the capacity for SL synthesis has been retained in the parasitic plant group. Inclusion of the non-SL-dependent related parasitic species Triphysaria versicolor and non-parasitic relatives Lindenbergia philippensis and Mimulus guttatus provide a comparative framework in which to judge gene evolution [34]. Here we report that all known genes associated with SLs have homologs in the SL-dependent parasites and provide evidence from gene expression and functional constraint analyses that the encoded proteins are functional.

\section{Materials and Methods}

\subsection{Plant Growth and Tissue Harvesting for Next-Generation Sequencing and qRT-PCR}

Several key stages of parasitic life style were selected for this study [see 34 for a detailed description]. P. aegyptiaca seeds were surface sterilized in $70 \%$ ethanol for 50 seconds, $1 \%$ sodium hypochlorite for $20 \mathrm{~min}, 0.01 \mathrm{M}$ HCL for $10 \mathrm{~min}$ and three successive rinses in sterile distilled water for $10 \mathrm{~min}$. For early stages, seeds were conditioned for $7 \mathrm{~d}$ on glass fiber paper in a Petri dish and then germinated with the addition of $2 \mathrm{mg} / \mathrm{L}$ of the synthetic germination stimulant GR24. Stages involving growth on host plants or in soil were generated as previously described [35].

Striga hermonthica seeds were surface sterilized, preconditioned and germinated as described previously by Gurney, et al. [36]. For haustorial stages, S. hermonthica haustoria were induced by the addition of $1 \mathrm{~mL}$ of 10 $\mu$ mol 2,6-dimethoxy-p-benzoquinone (DMBQ) to each Petri dish of pre-germinated Striga seeds [37]. For harvesting young $S$. hermonthica from host roots, Sorghum seeds were placed on a moistened glass fiber paper in a $90 \mathrm{~mm}$ Petri dish. Sorghum seedlings were germinated and then transferred into root observation chambers using the method described by Gurney, et al. [38]. Young parasite stages were harvested under a microscope using forceps or for later stages were cut from the host root and separated into shoots and roots. Mature vegetative and reproductive stages were prepared by growing the parasite with its host in $20 \mathrm{~cm}$ diameter pots filled with a soilsand mixture. Approximately 5000 non-preconditioned S. hermonthica seeds (40 mg fresh weight) were mixed 6 $\mathrm{cm}$ below the surface near the center of the pot and the soil-sand mixture was moistened with water. Sorghum seeds (24 h post-imbibition) were then planted in the Striga infested soil and the pot placed in the growth chamber as described above. The plants were watered with $150 \mathrm{ml}$ of half strength Peter's nutrient solution every day. Striga shoots emerged from the soil surface in 4 - 6 weeks. Stem, leaf and floral buds samples were harvested separately, flash frozen in liquid nitrogen, and stored at -80 C until used for nucleic acid preparation. Sequencing of individual stage-specific libraries was performed using 454 and Illumina sequencing technologies as previously described [34], with sequences available at http://ppgp.huck.psu.edu/.

\subsection{Identification of SL Genes in Parasites and Comparisons with Other Eudicot Sequences}

The latest assemblies of parasite transcriptomes from the PPGP database (P. aegyptiaca: OrAeBC5, S. hermonthica: StHeBC3, T. versicolor: TrVeBC3 and L. philippensis: LiPhGnB1) were matched against TAIR version 10 to identify the best BLAST Arabidopsis hit for each representative parasite contig. The resulting summary file was queried by using the AGI code of individual SL genes to identify the best BLAST hit parasite contig. Percentage sequence identities were calculated based on the global (genes with full length coding sequence) or local (genes with partial coding sequence) alignments of the translated amino acid sequences against the respective $A$. thaliana sequences. Of the best-match unigenes, the most complete versions were selected as the representative gene for a particular parasitic species and in some cases two unigenes were able to be joined to further extended the gene coverage. The translated amino acid sequences were used in multiple-sequence alignments with the respective Arabidopsis sequences to confirm the identity between sequences. For P. aegyptiaca CCD8, MAX1 and MAX2, Sanger sequence data were used in addition to PPGP data to generate the complete CDS sequences. No large unigene for $S$. hermonthica $C C D 7$ sequence was found in the PPGP database, but large frag- 
ments were obtained by two approaches. The 5' end was sequenced starting with degenerate primers based on homology to Arabidopsis and Pisum sequences, while the 3' end was found by searching a set of S. hermonthica genomic sequences. Transcriptome coverage for the closest nonparasitic relatives of the parasitic Orobanchaceae [39] [40], represented here by L. philippensis, was also generated as part of the PPGP.

\subsection{Phylogenetic and Functional Constraint Analyses}

Using version 6.5 of CLC Genomic Workbench RNA-Seq program (http://www.clcbio.com/

products/clc-genomics-workbench/), PCR duplicates were removed from read data before transcript abundance, FPKM (Fragments Per Kilobase of transcript per Million mapped reads) values were computed with unique reads counted to matching transcripts, and non-uniquely mapped reads allocated on a proportional basis relative to the number of uniquely mapped.

OrthoMCL [41] was used to classify genes from 22 selected plant genomes into narrowly defined gene families ("orthogroups") based on Markov Clustering of predicted amino acid sequences [42]. Candidate SL synthesis orthogroups were identified by retaining BLASTp [43] hits with e-value $\leq 1 \mathrm{e}^{-5}$ of predicted Orobanchaceae parasites SL synthesis genes searched on 22 plant genomes/proteomes that were classified in orthogroups. A profile hidden Markov model (pHMM) for each candidate orthogroup was then searched with the translated unigenes using hmm search as implemented in HMMER 3.0 [44], and unigenes were assigned to the orthogroup receiving the best bitscore. Amino-acid sequences of genes within each orthogroup containing a known or predicted SL synthesis gene were aligned to construct multiple sequence alignments using MAFFT [45]. Then cDNA sequences were forced onto the amino-acid alignments to create coding sequence (CDS) alignments using a customized perl script. Shorter sequences that did not cover $50 \%$ of the overall alignment length were removed, as were columns (base positions in the multiple sequence alignment) with gaps in more than $10 \%$ of the sequences [46]. The final CDS alignment was used to generate a maximum-likelihood phylogenetic tree using RAxML 7.2.1 [47] with the GTRGAMMA model. Branch support was evaluated by the bootstrap method, with 100 bootstrap replicates.

Selective constraint analysis was performed by the codeml program in Phylogenetic Analysis by Maximum Likelihood (PAML) [48] [49]. The branch test utilizing a likelihood ratio test was employed to infer if the SL-dependent parasite sequences (the "foreground" branches) have significantly different dN/dS ratio compared to the non-SL-dependent species sequences (the "background" branches). A one-ratio model and a two-ratio model, where the sequences of interest were labeled as the foreground, were run separately, after which the log likelihood ratios were extracted from the codeml output. Twice the difference of the log likelihood ratio follows a chi-square distribution with a degree of freedom of 1 ; this was used to test if the two-ratio model was significantly better than the one-ratio model. The multiple coding sequence alignment in PHYLIP format and a ML tree file were provided to run the codeml program.

\section{4. qRT-PCR Analyses}

Total RNA was isolated using TRIzol reagent (Invitrogen, USA) and further purified with RNeasy mini spin columns (Qiagen, USA). Quality and quantity of the DNase-treated RNA samples were assessed by Agilent Bioanalyzer 2100 analyses (Agilent Technologies, USA). First strand cDNA was synthesized using high capacity cDNA reverse transcription kit (Applied Biosystems) and Taqman chemistry was used to measure the expression level of the targeted SL genes in P. aegyptiaca (Table 1). For each developmental stage, three biological replicates and two technical replicates were used. Real time RT-PCR was performed (Applied Biosystems 7300 system) using a cycling regime of $95^{\circ} \mathrm{C}$ for $30 \mathrm{~s}$ followed by 40 cycles of $95^{\circ} \mathrm{C}$ for $15 \mathrm{~s}$ and $60^{\circ} \mathrm{C}$ for $1 \mathrm{~min}$. The default parameters of the SDS 7300 system software were used to determine the threshold cycle (Ct). The numbers of transcript copies were calculated based on an external standard curve and subsequently normalized based on input cDNA quantity. Phelipanche aegyptiaca ubiquitin 1 was used as the reference gene as it was found to be stably expressed across all life stages in the close relative $P$. (syn. Orobanche) ramosa [50]. The normalized values of transcript copy number in each biological sample were expressed as: (gene transcript copy number/transcript copy number of the reference gene) $\mathrm{X} 10^{5}$. Statistical analyses were performed in JMP 8 (SAS Institute Inc.).

\subsection{Bioassay of Striga Root Exudates on Phelipanche Seed Germination?}

Striga hermonthica seeds were surface-sterilized and germinated as described above. Germinated seedlings were 
Table 1. Taqman primers and probe sequences used for real-time RT PCR analyses of $P$. aegyptiaca genes.

\begin{tabular}{lccccc}
\hline $\begin{array}{c}\text { Name of } \\
\text { gene }\end{array}$ & Forward primer sequence (5'-3') & Probe sequence(5'-3') & Reverse primer sequence (5'-3') & $\begin{array}{c}\text { Amplicon } \\
\text { length (bp) }\end{array}$ \\
\hline PhAeCCD7 & CACGAGCGTGTTGCTATGG & TCCCACAAGCAAAACA GCAACGTCTTAACGTCAATCTCGTA & 83 \\
PhAeCCD8 & GCCCAACGATCGGAGATTTTCTAG & CCATCTTGCAAAACCT CTGTAATTGTCGATTGCTGTGAACA & 83 & 93 \\
PhAeMAX2 & CAGGAGTGTTTCAGGCTTAGGAA & ACGGCTCACGAGCACT & TCTCGTAAATCCGGTATCCTCAGT & 92 \\
PhAeUBQ1 & GGGAAGACGATAACCCTTGAAGTC TAGTGTCGGAGCTTTC & TCCCTTCCTTATCCTGAATCTTGGT & 95 \\
\hline
\end{tabular}

plated onto full strength Murashige \& Skoog medium (MS) supplemented with 3\% (w/v) of sucrose and 0.8\% $(\mathrm{w} / \mathrm{v})$ of agar adjusted to $\mathrm{pH} 5.75$ [51]. After four months growth in culture, the root exudate of $S$. hermonthica plants with well-developed root systems was collected and purified (slightly modified from [52]). Three S. hermonthica plants were separated from the MS medium, rinsed with sterile distilled water, and individually placed in glass tubes containing $3 \mathrm{ml}$ sterile distilled water. Plants were held in the tubes for $36 \mathrm{hr}$ to release the root exudates into the water. The solution containing the root exudate was filtered through sterile gauze and individually purified using reverse-phase chromatography on a C18 SEPAK cartridge. The root exudate solution (3 ml) was loaded onto pre-equilibrated columns and then eluted with $10 \mathrm{ml}$ sterile distilled water to first elute the more polar and inactive compounds on P. aegyptiaca germination. The columns were then eluted with $1 \mathrm{ml}$ of $100 \%$ methanol to obtain the more active compounds. After elution, the methanol was removed using Eppendorf vacufuge concentrator and stored at $-80^{\circ} \mathrm{C}$ until use. Three biological replicates were generated for each treatment.

Ability of extracts to stimulate parasitic seed germination was determined by bioassay using $P$. aegyptiaca seeds as described by [53]. Approximately 100 sterilized seeds were spread on 1.5-cm diameter glass fiber discs moistened with sterile distilled water and placed inside $10 \mathrm{~cm}$ Petri dishes and incubated in dark at $23^{\circ} \mathrm{C}$ for $7 \mathrm{~d}$ to allow seed conditioning. Discs containing P. aegyptiaca seeds were then blotted on sterile filter paper to remove excess moisture and again transferred to a new sterile Petri dish. Triplicate $100 \mu \mathrm{l}$ aliquots of $S$. hermonthica root exudate extract were applied to the discs containing the conditioned $P$. aegyptiaca seeds. Positive and negative controls (also in triplicate) were applied to additional discs containing $P$. aegyptiaca seeds. GR24 was used as positive control at $10^{-5} \mathrm{M}$, and sterile distilled water as negative control. After $7 \mathrm{~d}$ of further incubation, the germination was recorded in P. aegyptiaca seeds as a percentage of seeds with radicle emerged through the seed coat.

\section{Results}

\subsection{Genes for SL Biosynthesis and Signaling Are Present and Expressed in Parasitic Species}

Transcripts corresponding to known genes related to SL biosynthesis, signaling, and transport were found in the parasitic species $P$. aegyptiaca, S. hermonthica, and T. versicolor (Table 2). Of 24 genes considered (eight genes for each of three species), 16 were found with apparently complete coverage and 8 with incomplete coverage of the protein coding sequences. In most cases the full-length coding sequences identified in parasitic species were of comparable lengths to the reference $A$. thaliana sequences, with levels of amino acid identity greater than $55 \%$ for all full-length sequences. The finding of partial transcripts for some genes appears to be due to incomplete sequencing coverage as no premature termination codons were found. The lowest coverage was found for CCD7 of T. versicolor, consisting of three fragments of $24-35$ amino acids. However, this low level of $C C D 7$ sequence may be due to low gene expression or vagaries of sequencing coverage rather than loss of the gene, as full or nearly full coverage of $C C D 7$ homologs were identified in the SL responsive species $P$. aegyptiaca and $S$. hermonthica, and there is no reason to expect that $T$. versicolor, which does not require SLs for germination, should differ from other plants that have the typical SL biosynthetic pathway. A CCD7 gene has also been sequenced from the related parasite, Phelipanche ramosa, and is $98 \%$ identical to the P. aegyptiaca CCD7 protein [54].

\subsection{Phylogenetic Relationships of the SL Genes in Parasites}

To study the phylogenetic relationships of the identified parasite genes, we compared these sequences with ho- 
Table 2. Identification and coverage of transcripts related to strigolactone (SL) biosynthesis, signaling and transport in three parasitic plant species.

\begin{tabular}{|c|c|c|c|c|c|}
\hline $\begin{array}{l}\text { Characterized SL } \\
\text { genes }\end{array}$ & Role in SL pathway & A. thaliana reference & P. aegyptiaca & S. hermonthica & T. versicolor \\
\hline & & $\begin{array}{c}\text { Accession } \\
\text { (Amino acid length) }\end{array}$ & \multicolumn{3}{|c|}{$\begin{array}{c}\text { Extent of coding sequence identified } \\
\text { (Amino acid length, identity to } A \text {. thaliana) }\end{array}$} \\
\hline $\mathrm{D} 27^{\mathrm{Os}^{*}}$ & Biosynthesis of SL precursor & $\begin{array}{l}\text { AT1G03055 } \\
\quad(264)\end{array}$ & $\begin{array}{c}\text { Full } \\
(251,41.9 \%)\end{array}$ & $\begin{array}{c}\text { Partial } \\
(73,53.6 \%)\end{array}$ & $\begin{array}{c}\text { Partial } \\
(232,41.0 \%)\end{array}$ \\
\hline $\begin{array}{c}\text { CCD7/MAX3 } 3^{\mathrm{At}}, \\
\mathrm{RMS5}^{\mathrm{Ps}}, \mathrm{D} 17^{\mathrm{Os}}, \\
\mathrm{DAD3}^{\mathrm{Ph}}\end{array}$ & Biosynthesis of SL precursor & $\begin{array}{l}\text { AT2G44990 } \\
\quad(629)\end{array}$ & $\begin{array}{c}\text { Full } \\
(652,55.3 \%)\end{array}$ & $\begin{array}{c}\text { Partial } \\
(533,45.2 \%)\end{array}$ & Fragments \\
\hline $\begin{array}{c}\text { CCD8/MAX4 } 4^{\mathrm{At}}, \\
\mathrm{RMS1}^{\mathrm{Ps}}, \mathrm{D} 10^{\mathrm{Os}}, \\
\text { DAD1 } 1^{\mathrm{Ph}}\end{array}$ & $\begin{array}{l}\text { Biosynthesis of } \\
\text { carlactone }\end{array}$ & $\begin{array}{l}\text { AT4G32810 } \\
\quad(570)\end{array}$ & $\begin{array}{c}\text { Full } \\
(563,60.3 \%)\end{array}$ & $\begin{array}{c}\text { Partial } \\
(214,67.8 \%)\end{array}$ & $\begin{array}{c}\text { Partial } \\
(279,65.7 \%)\end{array}$ \\
\hline $\mathrm{MAX}^{\mathrm{At}}$ & $\begin{array}{l}\text { Conversion to } \\
\text { bioactive SL }\end{array}$ & $\begin{array}{l}\text { AT2G26170 } \\
\quad(522)\end{array}$ & $\begin{array}{c}\text { Full } \\
(526,68.5 \%)\end{array}$ & $\begin{array}{c}\text { Full } \\
(523,65.8 \%)\end{array}$ & $\begin{array}{c}\text { Full } \\
(478,65.5 \%)\end{array}$ \\
\hline $\begin{array}{c}\mathrm{MAX2}^{\mathrm{At}}, \mathrm{RMS}^{\mathrm{Ps}}, \\
\mathrm{D} 3^{\mathrm{Os}}\end{array}$ & $\begin{array}{c}\text { Mediates signaling } \\
\text { (Both SL and karrikin signals) }\end{array}$ & $\begin{array}{l}\text { AT2G42620 } \\
\quad(693)\end{array}$ & $\begin{array}{c}\text { Full } \\
(709,55.9 \%)\end{array}$ & $\begin{array}{c}\text { Full } \\
(703,56.6 \%)\end{array}$ & $\begin{array}{c}\text { Partial } \\
(296,50.3 \%)\end{array}$ \\
\hline $\mathrm{D} 14^{\mathrm{Os}}, \mathrm{DAD} 2^{\mathrm{Ph}}$ & $\begin{array}{l}\text { Signal perception } \\
\text { (SL binding) }\end{array}$ & $\begin{array}{l}\text { AT3G03990 } \\
\quad(267)\end{array}$ & $\begin{array}{c}\text { Full } \\
(266,77.2 \%)\end{array}$ & $\begin{array}{c}\text { Partial } \\
(180,76.8 \%)\end{array}$ & $\begin{array}{c}\text { Full } \\
(273,62.1 \%)\end{array}$ \\
\hline $\mathrm{KAI}^{\mathrm{At}}$ & $\begin{array}{l}\text { Homolog of D14. Related to } \\
\text { karrikin signaling. }\end{array}$ & $\begin{array}{l}\text { AT4G37470 } \\
\quad(270)\end{array}$ & $\begin{array}{c}\text { Full } \\
(270,75.2 \%)\end{array}$ & $\begin{array}{c}\text { Full } \\
(271,75.6 \%)\end{array}$ & $\begin{array}{c}\text { Full } \\
(272,73.9 \%)\end{array}$ \\
\hline $\mathrm{PDR}_{12}^{\mathrm{At}}, \mathrm{PDR} 1^{\mathrm{Ph}}$ & SL transport & AT1G15520 (1423) & $\begin{array}{c}\text { Full } \\
(1428,69.0 \%)\end{array}$ & $\begin{array}{c}\text { Full } \\
(1440,68.3 \%)\end{array}$ & $\begin{array}{c}\text { Full } \\
(1491.67 .2 \%)\end{array}$ \\
\hline
\end{tabular}

*Identities of the plants where the respective genes have been characterized are indicated by superscript: At, Arabidopsis thaliana; Os, Oryza sativa; Ph, Petunia hybrida; Ps, Pisum sativum.

mologous coding sequences from two closely related non-parasitic species L. philippensis and M. guttatus, as well as 22 other core eudicots. For all SL-related genes, the sequences from parasitic species always formed a well-supported clade with L. philippensis and M. guttatus, but separate from other species (Figure 1) and overall consistent with previously reported phylogenies [23]. However, only for CCD7, MAX1 (Figure 1(b)), and MAX2 (data not shown) did the SL germination dependent species $P$. aegyptiaca and $S$. hermonthica form a separate clade from the SL independent species. This analysis included all genes in Table 2, except for PDR1, which is part of a multigene family that produced a large and poorly resolved tree (not shown).

\subsection{SL Genes Are under Functional Constraint in Parasites}

We then investigated whether selective constraints on SL genes in SL-requiring species differ from those on non-SL-requiring species. Genes encoding proteins that function in SL biosynthesis would be expected to show signatures of selective constraint, so SL genes were subjected to dN/dS analysis in PAML. A dN/dS (w) ratio greater than 1 , equal to 1 , and less than 1 , indicates positive selection, neutral evolution, and purifying selection, respectively [55]. We first tested whether parasite genes were evolving differently from non-parasite genes and found that only MAX1 was significant for any selective constraint, exhibiting purifying selection (Table 3). This suggests that MAX1is a functionally conserved protein and that selection has not permitted many nonsynonymous mutations in the parasitic species. We then tested S. hermonthica and P. aegyptiaca as a group to determine whether SL dependence was associated with specific selection types. Analyzed this way, CCD7 showed relaxation, suggesting that this gene is subject to evolutionary constraints that differ from the same gene in non-SLrequiring plants. In comparison, genes involved in SL perception in SL-dependent species appear to be evolving in a manner similar to that of non-SL-dependent species.

To gain further insight into the potential that these genes encode functional proteins, we searched for the presence of known signatures/motifs that have been characterized in homologous genes from other plant systems. Four amino acid residues have been implicated in binding specificity of maize 9-cis epoxy carotenoid dioxygenase (NCED) proteins [56] and subsequently shown to be highly conserved in CCD7 and CCD8 across all plants [13] [23]. Two other conserved regions are recognized in CCD7 and one in CCD8 [23]. Overall, these 


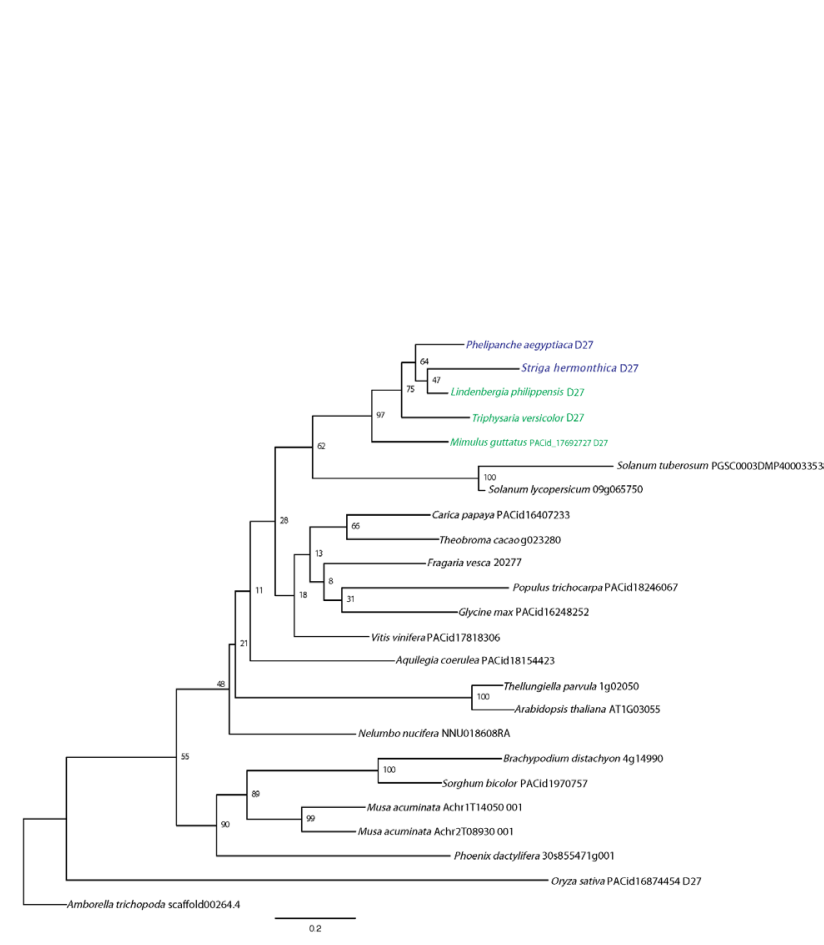

(a)

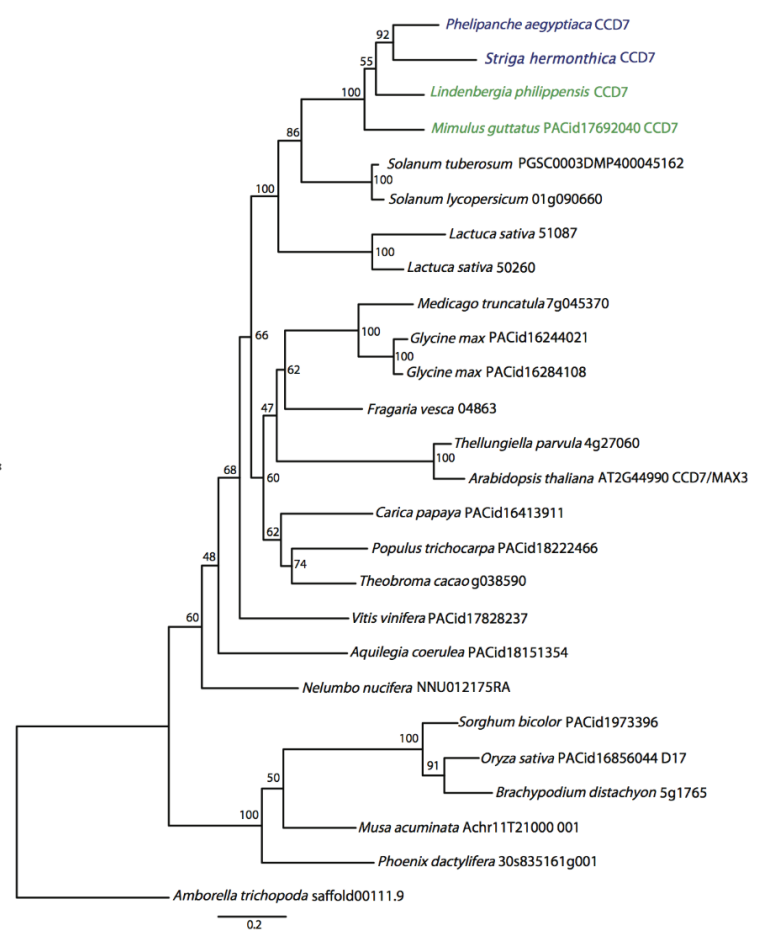

(b)

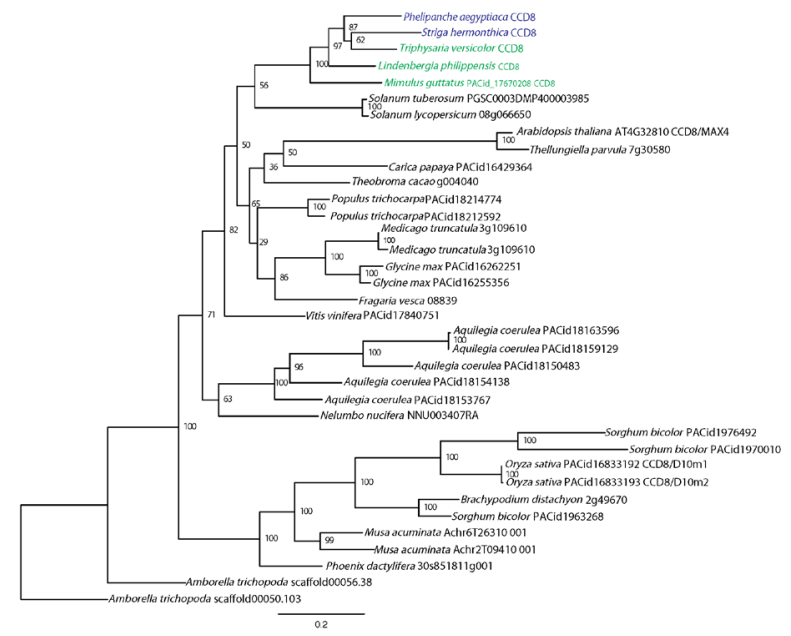

(c)

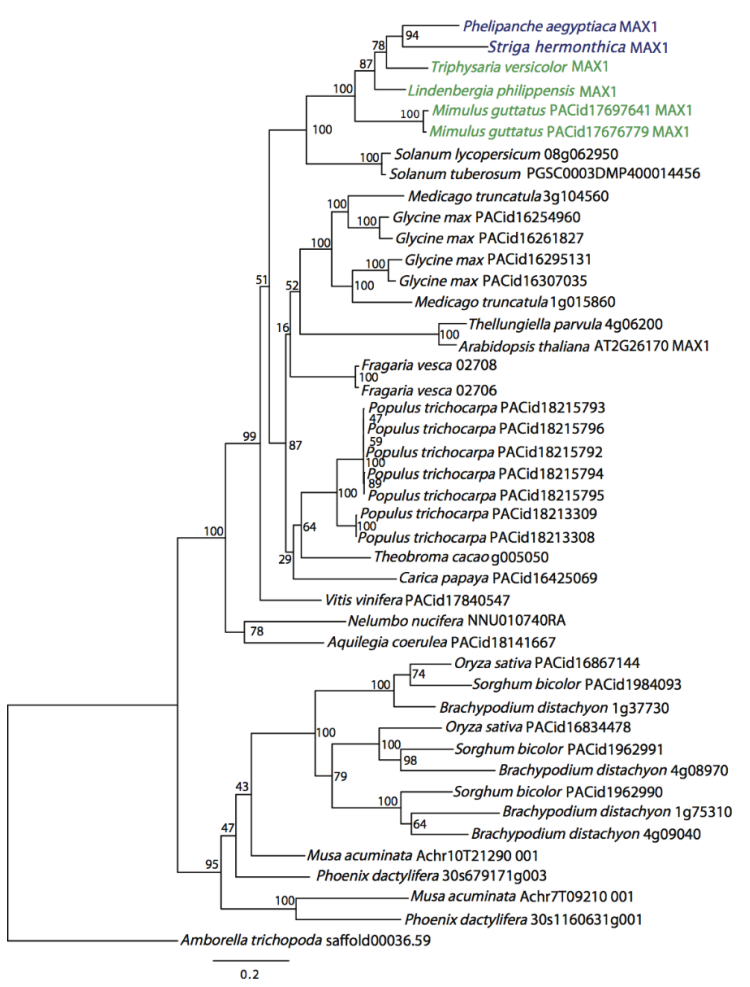

(d)

Figure 1. Phylogenetic trees for angiosperm orthologs of genes related to strigolactone synthesis. (a) D27, (b) CCD7, (c) CCD8 and (d) MAX1. SL-dependent parasites are shown in blue font, with non-SL-dependent relatives in green font. Maximum likelihood trees are shown with bootstrap values from 100 bootstrap replicates. 
Table 3. Summary of selective constraint analysis for strigolactone-related genes in studied species as grouped by strigolactone (SL)-dependent species or all parasite species as compared to the homologous genes from other species (see Figure 1).

\begin{tabular}{|c|c|c|c|c|c|}
\hline Gene & Type of selection & Foreground w & Background w & p-value & Significance \\
\hline \multicolumn{6}{|c|}{ All parasite species $P$. aegyptiaca, S. hermonthica and $T$. versicolor as foreground } \\
\hline D27 & NA & 0.313 & 0.259 & 0.804 & NS \\
\hline CCD7 & nd & & & & \\
\hline CCD8 & NA & 0.124 & 0.157 & 0.056 & NS \\
\hline MAX1 & Strong purifying & 0.059 & 0.191 & 0.024 & * \\
\hline MAX2 & NA & 0.192 & 0.177 & 0.730 & NS \\
\hline D14 & NA & 0.107 & 0.077 & 0.605 & NS \\
\hline \multicolumn{6}{|c|}{ SL-dependent species $P$. aegyptiaca and $S$. hermonthica as foreground } \\
\hline D27 & NA & 0.200 & 0.259 & 0.804 & NS \\
\hline CCD7 & Relaxation & 0.735 & 0.191 & 0.012 & $*$ \\
\hline CCD8 & NA & 0.137 & 0.156 & 0.774 & NS \\
\hline MAX1 & NA & 0.087 & 0.190 & 0.220 & NS \\
\hline MAX2 & NA & 0.253 & 0.177 & 0.640 & NS \\
\hline D14 & NA & 0.087 & 0.078 & 0.890 & NS \\
\hline
\end{tabular}

nd indicates not determined because of insufficient sequence for $T$. versicolor CCD7.

amino acids and associated regions were found to be similarly conserved in the Orobanchaceae species tested, regardless of SL dependency (Figure 2). Each of the key amino acid positions in P. aegyptiaca are conserved, though missing sections of S. hermonthica CCD7 and CCD8 sequences limit drawing a definitive conclusion. We also found that $P$. aegyptiaca and $S$. hermonthica differ from their non-SL-requiring relatives at two positions within the conserved CCD8 motif from amino acid residues 329 - 340. The R-330-T/R change is found in other species while the Y-337-F is highly conserved [23]. The functional impact of these substitutions is unclear and will require additional research to elucidate their importance. In terms of other genes associated with SL signaling, conserved regions of the MAX2 protein that are implicated in substrate binding [13] are found in all parasite species, and the SL transporter PDR12 [31] [57] shows retention of all conserved ABCG/PDR domains (Data not shown). Taken together these analyses indicate that the identified SL biosynthetic, signaling and transporter genes retain signatures consistent with their known biological functions.

\subsection{SL Genes Are Regulated in Tissue- and Developmental Stage-Specific Patterns}

Further evidence that genes are functional could be provided by development-specific expression patterns, so we calculated the normalized expression levels (FPKM is the count of mapped transcript fragments to this gene per kilobase of sequence length per million library reads) of each SL gene in each library or developmental stage of the PPGP data [34]. In P. aegyptiaca all of the first three genes involved in SL biosynthesis (D27, CCD7, and CCD8) are expressed predominantly in underground shoots and roots (Figure 3(a)). This finding is consistent with roots being a major site of SL biosynthesis [58]. Similarly, in S. hermonthica, D27 and CCD8 transcript levels are highest in roots (Figure 3(b)). MAX1was consistently expressed across developmental stages in both species. The similarity in expression pattern in P. aegyptiaca and $S$. hermonthica suggests that they are under similar modes of transcriptional regulation.

In contrast to the trend observed for the SL biosynthetic genes, the SL receptor/signaling genes MAX2 and $D 14$ are expressed throughout the life cycles of $P$. aegyptiaca and $S$. hermonthica (Figure 3). This is consistent with the pattern of expression observed in $P$. sativum where MAX2/RMS4 was constitutively expressed across 


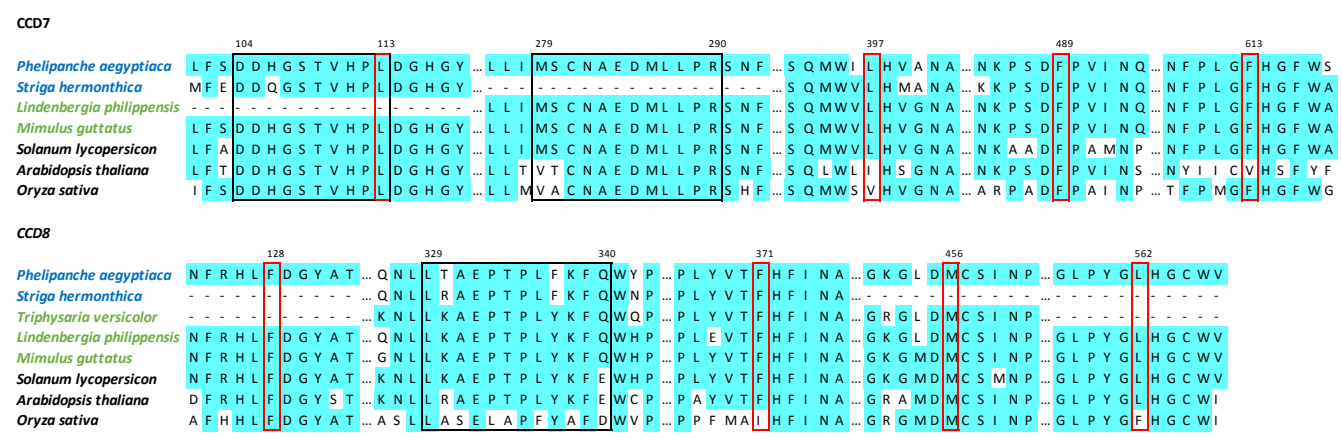

Figure 2. Partial alignments of CCD7 and CCD8 amino acid sequences for Orobanchaceae parasites, non-parasitic relatives, and three other species. SL-dependent parasites are shown in blue font, with non-SL-dependent relatives in green font. Red boxes indicate residues identified as important in substrate binding and black boxes indicate other conserved regions [23]. Numbering is based on Arabidopsis sequences.
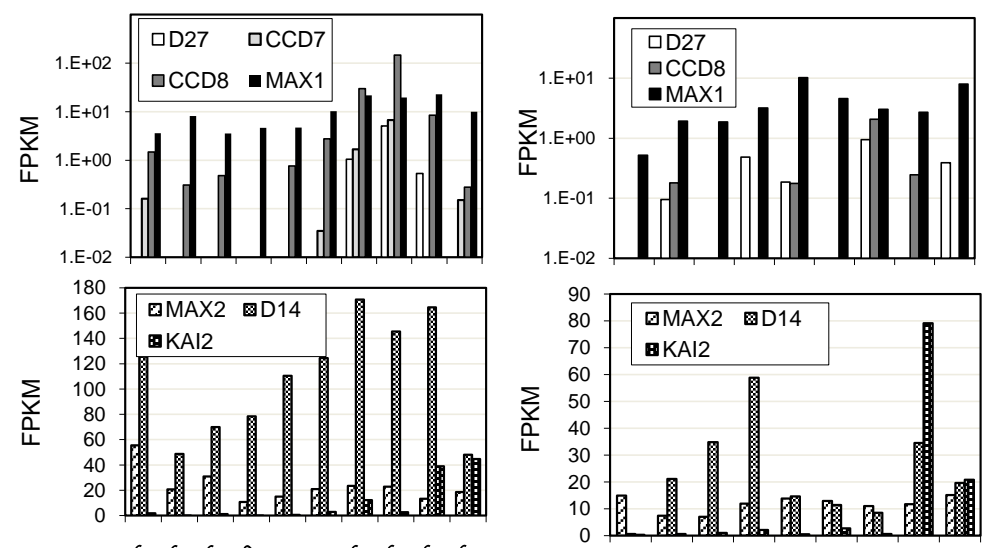

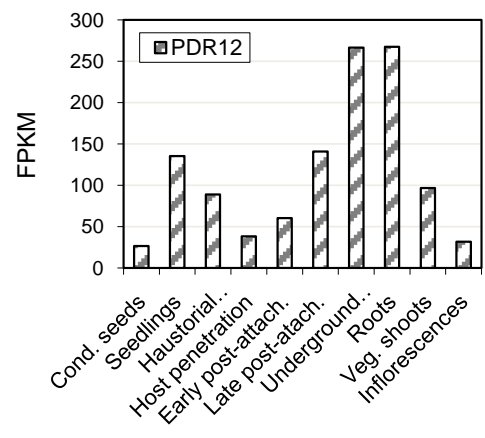

(a)
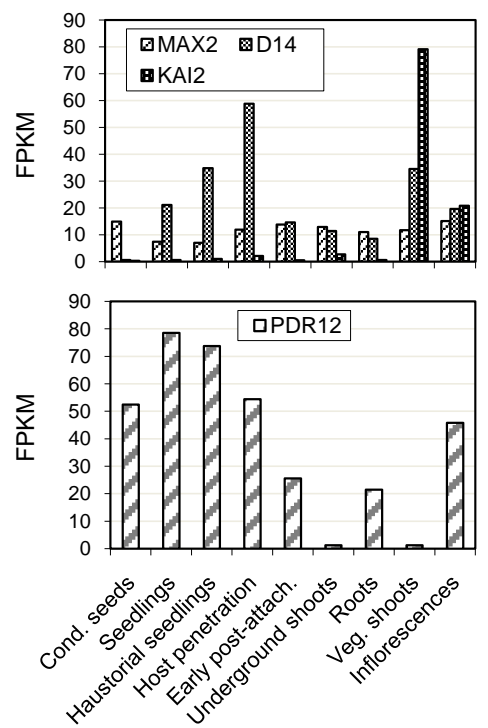

(b)

Figure 3. Expression levels of SL-related gene transcripts as indicated by RNA-seq in P. aegyptiaca (a) and S. hermonthica (b); Normalized expression levels were calculated for each stage-specific library and expressed as FPKM. Abbreviations: Cond. seeds, conditioning seeds; post-attach., post attachment to host; Veg. shoots, vegetative shoots.

tissue types [59]. Expression of KAI2 was low or lacking in early development of both species, reaching its maximum in vegetative shoots or inflorescences. The SL transporter PDR1 was expressed in all stages of both species, though with no consistent pattern associated with development.

To verify gene expression from RNA-seq data and enhance resolution at early stages of the parasite life cycle that play a crucial role in detecting the presence of host roots, we measured the expression levels of three selected genes (CCD7, CCD8, MAX2) in P. aegyptiaca using q-RT-PCR (Figure 4). CCD7 expression declined between days 4 and 7 of conditioning and was not detected in germinating seedlings (Figure 4(a)). Low expression of CCD7 in germinating seedlings was also found in S. hermonthica [33], although it is not clear whether this is due to developmental regulation or to feedback regulation of SL biosynthetic genes [60] caused by use of 


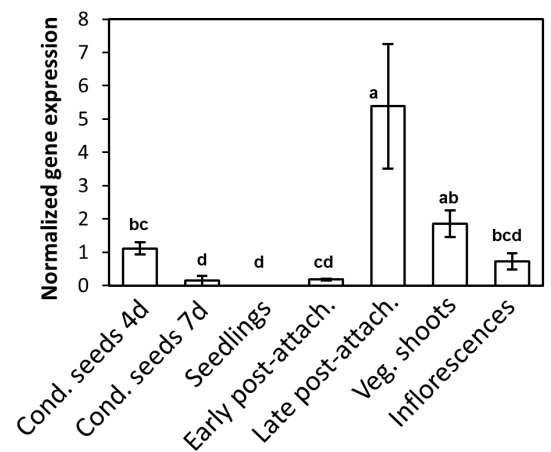

(a)

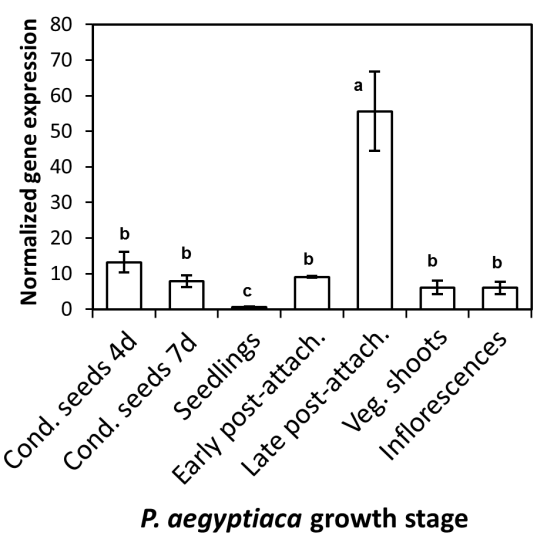

(b)

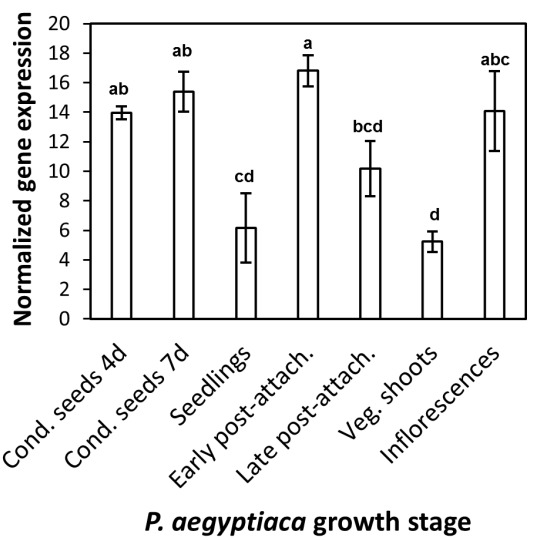

(c)

Figure 4. The expression of genes for key strigolactone biosynthetic enzymes CCD7 (a) and CCD8 (b) and the putative strigolactone receptor MAX2 (c) across developmental stages of $P$. aegyptiaca. RNA levels were measured by quantitative RT-PCR and presented as copy number of target gene/copy number of expression of ubiquitin $1 \times 10^{5}$. Each bar represents the mean of three biological replicates $+/-$ SE. Bars with different letters are significantly different according to the Tukey test $(p=0.05)$. Abbreviations are as described in Figure 3 except that days of conditioning are specified as 4 or 7.

GR24 to induce seed germination. CCD8 expression followed a similar trend, but was significantly lower only in germinating seedlings (Figure 4(b)). Both CCD7 and CCD8 had highest expression in the late post-attachment underground stage, at which time the tubercles are characterized by high numbers of roots. The expression level of MAX2 was steady during seed conditioning, and lower in germinated seedlings and vegetative shoots, but otherwise consistent across developmental stages (Figure 4(c)). Similar analysis in S. hermonthica indicated highest expression of CCD7 during the first week of conditioning, then decreasing by $14 \mathrm{~d}$ and in germinated seedlings similar to the trend in $P$. aegyptiaca but extended over a longer required conditioning period for $S$. hermonthica.

\subsection{Striga root Exudates Can Induce Germination of Phelipanche Seeds}

To confirm the presence of SL class stimulants in parasitic plants, we collected root exudates from $S$. hermonthica plants grown in vitro in the absence of a host. The crude root exudate was purified on a C18 column to isolate the SL containing fraction and applied in three different dilutions to conditioned P. aegyptiaca seeds. The negative control induced negligible spontaneous germination, while the SL analog GR24 positive control induced germination above $80 \%$. Striga root exudate applied in three different concentrations induced germination of $P$. aegyptiaca seeds, with only the lowest dilution lacking statistical separation from the negative control (Figure 5). Although this observation does not exclude the possibility of presence of additional substances other than SLs in the root exudates with potential role for broomrape germination [61]-[63], it points to the possibility that the SL pathway identified in this study reflects real production of SLs in the SL-dependent parasitic plant group. It is noteworthy that a similar experiment conducted independently reached the same conclusion [33]. 


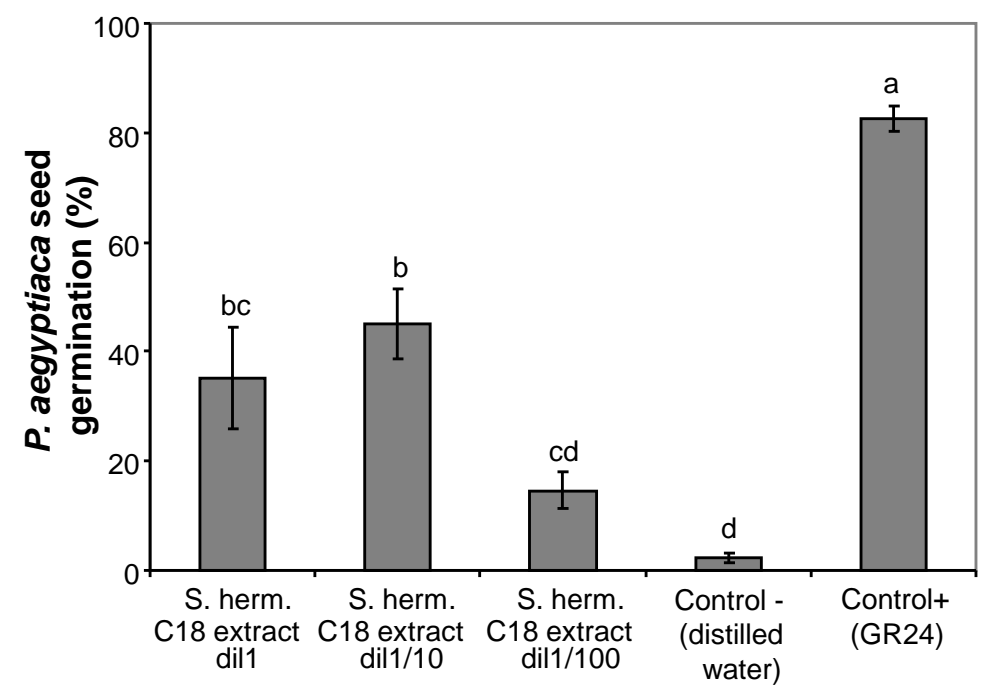

Figure 5. Effect of $S$. hermonthica root exudates on $P$. aegyptiaca seed germination. Each bar represents the mean of three biological replicates $+/-$ SE. Bars with different letters are significantly different according to the Tukey test $(p=0.05)$.

\section{Discussion}

The decades-old discovery that certain parasitic Orobanchaceae species germinate in response to host-derived SL germination stimulants [1] raised the paradox of why plants would exude such chemicals when reduced exudation should result in less parasite seed germination. The answer that has emerged in recent years is that the SLs are a signal to mycorrhizal fungi colonization [5] and are important mediators of the plant's response to the environment, particularly under conditions of phosphate starvation [4] [64] [65]. At the same time these compounds serve as mobile signals within the plant to regulate shoot architecture, which can also serve the plant by limiting branching under phosphate-limiting conditions [58] [66]-[69]. Thus, SLs appear to be critical to plant development and interaction with beneficial microorganisms and there is strong selective pressure to maintain SL biosynthesis and signaling. However, parasitic plants should be the one class of plants that would seem to benefit from a lack of SL production, given the strong evolutionary pressure on them to detect exogenous SLs in the environment, combined with the lack of penalty for giving up associations with arbuscular mycorrhizal fungi, since they obtain phosphate and nitrogen from their hosts [70].

The findings of our study suggest that parasitic plants have retained a functional SLs biosynthetic pathway similar to other plants. If in fact parasites would benefit from a lack of SL production, a simple mutation resulting in translation termination of any of the key SL biosynthetic genes would suffice. Over evolutionary time, one would expect genes such as $D 27, C C D 7$, or $C C D 8$ to accumulate multiple deleterious mutations or even be lost from the genome as has occurred for light harvesting genes in holoparasites [71] [72]. On the contrary, transcriptome sequencing of $P$. aegyptiaca and $S$. hermonthica revealed that the genes are all present with apparently full-length proteins (Table 2). Analysis of these proteins resulted in phylogenies consistent with previous hypotheses of relationships in this group (Figure 1) and show evidence of functional constraint (Table 3, Figure 2), indicating continued purifying selection. Furthermore, the genes are expressed in developmental patterns that are consistent with some of the known regulation of SL biosynthetic genes in other plants, such as the apparent transcriptional co-regulation of $C C D 7$ and $C C D 8$ genes across tissue types which mirror that in $A$. thaliana and Pisum sativum (Figure 3 and Figure 4) [19] [59]. We also find similar evidence of genes implicated in SL perception, such as MAX2 and D14 (and the related karrikin-responsive KAI2), as well as the SL transporter $P D R 12$. The retention of SL signaling genes is anticipated given the dependence of $P$. aegyptiaca and $S$. hermonthica on detecting host SLs. Considering that $S$. hermonthica MAX2 has been demonstrated to retain function in a heterologous system [33], our data point to intact SL biosynthetic and perception systems in these plants.

The data for SL synthesis by parasites presented here is substantial, but indirect. The bioassay showing stimulatory effect of $S$. hermonthica root extracts on P. aegyptiaca seeds (Figure 5) addresses this, although it falls short of identifying a true parasite SL using analytical methods. These results mirror those obtained in an 
independent study where cultured $S$. hermonthica extracts stimulated germination of $P$. ramosa seeds [33]. Bioassays are still the most sensitive method for detecting SLs and provide corroboration for the gene retention data. The current result should spur researchers to begin looking for SLs in parasitic plant exudates and extracts.

The presence of a functional and regulated SL synthetic pathway substantially shifts thinking about SLs in parasite biology from how parasites detect host SLs to how they differentiate host SLs from endogenous SLs. It is possible that parasites make this distinction based on timing, localization, or structural specificity of SL production. The current data on gene expression suggest that SL synthesis occurs in seeds during the early phase of conditioning, but is shut down as the seed becomes competent for germination, perhaps allowing the seed to avoid conflict between endogenous and exogenous SLs. With respect to localization, recent work has suggested that SL detection is localized to the micropylar end of the Phelipanche seed [73] so spatial separation of SL biosynthesis away from this area may effectively serve the same purpose. It is also possible to speculate that parasites produce unique SLs that are specifically recognized by processes separate from the germination-related response to host SLs. Plants produce multiple variants of SLs [74] [75], and it is possible that these are recognized by specific receptors as evidenced by Phelipanche and Orobanche species remarkable ability to differentiate host germination stimulants [76] [77]. Our data suggest that $P$. aegyptiaca recognizes a SL produced by $S$. hermonthica, which is perhaps not surprising given that $P$. aegyptiaca is among the more permissive species, responding to a wide variety of SLs [76].

Finally, these findings suggest that SLs are essential to plant development and are not lost even when there would seem to be an evolutionary advantage to doing so. It does not appear that parasitic plants require communication with mycorrhizal fungi to enhance nutrient uptake, and therefore there would appear to be little benefit to retain this feature. However, SLs may also be important in other rhizosphere communication that is not yet understood. In addition, SLs may regulate shoot branching patterns in parasites just as in other eudicots, and Liu et al. [33] suggest that SLs are important in regulating branching in Striga. SL hormones are evolutionarily ancient and understanding of their role in coordinating plant development is rapidly expanding [14] [32]. The current work contributes to this body of knowledge by demonstrating that parasitic plant synthesis of SLs and use as germination triggers is likely more sophisticated than initially expected.

\section{Conclusion}

The role of SLs in stimulating germination of parasitic plants has been long established. The finding that SLs are also evolutionarily conserved plant hormones with a multitude of roles in development and rhizosphere signaling causes us to investigate the potential ability of $P$. aegyptiaca and $S$. hermonthica to synthesize endogenous SLs. Our data suggest that SL biosynthetic capacity has been retained in these species, raising new questions about how parasites regulate SL production and detection to enable specific detection of exogenous SLs for seed germination.

\section{Availability of Supporting Data}

The data sets supporting the results of this article are available in the Parasitic Plant Genome Project website http://ppgp.huck.psu.edu/ and NCBI Parasitic Plant Genome Project SRA accession, SRP001053 (http://www.ncbi.nlm.nih.gov/sra/?term=SRP001053).

\section{Acknowledgements}

We are grateful to Hailey Larose (Virginia Tech) and Shayani Das Laha (Presidency University) for additional work extending sequences of genes related to SL biosynthesis. This research was supported by National Science Foundation grants DBI-0701748 and IOS-1238057 to J.H.W., C.D., M.P.T. and J.I.Y., with additional support from National Institute of Food and Agriculture (NIFA) Project No. 135997 (J.H.W.), the Marie Curie postdoctoral fellowship PIOF-GA-2009-252538 (M.F.-A.), NSF award IBN-0322420 and Kirkhouse Trust (M.P.T. and K.H.), and the Department of Biology, and Plant Biology Graduate Program at Penn State University (C.D., Z.Y., N.W. and E.K.W.).

\section{References}

[1] Cook, C.E., Whichard, L.P., Turner, B., Wall, M.E. and Egley, G.H. (1966) Germination of Witchweed (Striga lutea 
Lour.): Isolation and Properties of a Potent Stimulant. Science, 154, 1189-1190. http://dx.doi.org/10.1126/science.154.3753.1189

[2] Cook, C.E., Whichard, L.P., Wall, M.E., Egley, G.H., Coggon, P., Luhan, P.A. and McPhail, A.T. (1972) Germination Stimulants. II. Structure of Strigol, a Potent Seed Germination Stimulant for Witchweed (Striga lutea). Journal of the American Chemical Society, 94, 6198-6199. http://dx.doi.org/10.1021/ja00772a048

[3] Matusova, R., Rani, K., Verstappen, F.W.A., Franssen, M.C.R., Beale, M.H. and Bouwmeester, H.J. (2005) The Strigolactone Germination Stimulants of the Plant-Parasitic Striga and Orobanche Spp. Are Derived from the Carotenoid Pathway. Plant Physiology, 139, 920-934. http://dx.doi.org/10.1104/pp.105.061382

[4] Lopez-Raez, J.A., Charnikhova, T., Gomez-Roldan, V., Matusova, R., Kohlen, W., De Vos, R., Verstappen, F., Puech-Pages, V., Becard, G., Mulder, P. and Bouwmeester, H. (2008) Tomato Strigolactones Are Derived from Carotenoids and Their Biosynthesis Is Promoted by Phosphate Starvation. New Phytologist, 178, 863-874. http://dx.doi.org/10.1111/j.1469-8137.2008.02406.x

[5] Akiyama, K., Matsuzaki, K.-I. and Hayashi, H. (2005) Plant Sesquiterpenes Induce Hyphal Branching in Arbuscular Mycorrhizal Fungi. Nature, 435, 824-827. http://dx.doi.org/10.1038/nature03608

[6] Zheng, Z., Germain, A.D.S. and Chory, J. (2014) Unfolding the Mysteries of Strigolactone Signaling. Molecular Plant, 7, 934-936. http://dx.doi.org/10.1093/mp/ssu021

[7] Waldie, T., McCulloch, H. and Leyser, O. (2014) Strigolactones and the Control of Plant Development: Lessons from Shoot Branching. The Plant Journal, 79, 607-622. http://dx.doi.org/10.1111/tpj.12488

[8] Seto, Y. and Yamaguchi, S. (2014) Strigolactone Biosynthesis and Perception. Current Opinion in Plant Biology, 21, 1-6. http://dx.doi.org/10.1016/j.pbi.2014.06.001

[9] Koltai, H. (2014) Receptors, Repressors, PINs: A Playground for Strigolactone Signaling. Trends in Plant Science, 19, 727-733. http://dx.doi.org/10.1016/j.tplants.2014.06.008

[10] Bennett, T. and Leyser, O. (2014) Strigolactone Signalling: Standing on the Shoulders of DWARFs. Current Opinion in Plant Biology, 22, 7-13. http://dx.doi.org/10.1016/j.pbi.2014.08.001

[11] Bonfante, P. and Genre, A. (2008) Plants and Arbuscular Mycorrhizal Fungi: An Evolutionary-Developmental Perspective. Trends in Plant Science, 13, 492-498. http://dx.doi.org/10.1016/j.tplants.2008.07.001

[12] Proust, H., Hoffmann, B., Xie, X., Yoneyama, K., Schaefer, D.G., Yoneyama, K., Nogué, F. and Rameau, C. (2011) Strigolactones Regulate Protonema Branching and Act as a Quorum Sensing-Like Signal in the Moss Physcomitrella patens. Development, 138, 1531-1539. http://dx.doi.org/10.1242/dev.058495

[13] Delaux, P.-M., Xie, X., Timme, R.E., Puech-Pages, V., Dunand, C., Lecompte, E., Delwiche, C.F., Yoneyama, K., Bécard, G. and Séjalon-Delmas, N. (2012) Origin of Strigolactones in the Green Lineage. New Phytologist, 195, 857871. http://dx.doi.org/10.1111/j.1469-8137.2012.04209.x

[14] Wang, C., Liu, Y., Li, S.-S. and Han, G.-Z. (2015) Insights into the Origin and Evolution of the Plant Hormone Signaling Machinery. Plant Physiology, 167, 872-886. http://dx.doi.org/10.1104/pp.114.247403

[15] Tsuchiya, Y. and McCourt, P. (2012) Strigolactones as Small Molecule Communicators. Molecular BioSystems, 8, 464-469. http://dx.doi.org/10.1039/C1MB05195D

[16] Xie, X., Yoneyama, K. and Yoneyama, K. (2010) The Strigolactone Story. Annual Review of Phytopathology, 48, 93117. http://dx.doi.org/10.1146/annurev-phyto-073009-114453

[17] Lin, H., Wang, R., Qian, Q., Yan, M., Meng, X., Fu, Z., Yan, C., Jiang, B., Su, Z., Li, J. and Wang, Y. (2009) DWARF27, an Iron-Containing Protein Required for the Biosynthesis of Strigolactones, Regulates Rice Tiller Bud Outgrowth. The Plant Cell, 21, 1512-1525. http://dx.doi.org/10.1105/tpc.109.065987

[18] Alder, A., Jamil, M., Marzorati, M., Bruno, M., Vermathen, M., Bigler, P., Ghisla, S., Bouwmeester, H., Beyer, P. and Al-Babili, S. (2012) The Path from $\beta$-Carotene to Carlactone, a Strigolactone-Like Plant Hormone. Science, 335, 13481351. http://dx.doi.org/10.1126/science.1218094

[19] Auldridge, M.E., Block, A., Vogel, J.T., Dabney-Smith, C., Mila, I., Bouzayen, M., Magallanes-Lundback, M., DellaPenna, D., McCarty, D.R. and Klee, H.J. (2006) Characterization of Three Members of the Arabidopsis Carotenoid Cleavage Dioxygenase Family Demonstrates the Divergent Roles of This Multifunctional Enzyme Family. The Plant Journal, 45, 982-993. http://dx.doi.org/10.1111/j.1365-313X.2006.02666.X

[20] Sorefan, K., Booker, J., Haurogné, K., Goussot, M., Bainbridge, K., Foo, E., Chatfield, S., Ward, S., Beveridge, C., Rameau, C. and Leyser, O. (2003) $M A X_{4}$ and $R M S_{1}$ Are Orthologous Dioxygenase-Like Genes That Regulate Shoot Branching in Arabidopsis and Pea. Genes \& Development, 17, 1469-1474. http://dx.doi.org/10.1101/gad.256603

[21] Turnbull, C.G.N., Booker, J.P. and Leyser, H.M.O. (2002) Micrografting Techniques for Testing Long-Distance Signalling in Arabidopsis. The Plant Journal, 32, 255-262. http://dx.doi.org/10.1046/j.1365-313X.2002.01419.x

[22] Schwartz, S.H., Qin, X. and Loewen, M.C. (2004) The Biochemical Characterization of Two Carotenoid Cleavage 
Enzymes from Arabidopsis Indicates That a Carotenoid-Derived Compound Inhibits Lateral Branching. Journal of Biological Chemistry, 279, 46940-46945. http://dx.doi.org/10.1074/jbc.M409004200

[23] Challis, R.J., Hepworth, J., Mouchel, C., Waites, R. and Leyser, O. (2013) A Role for More AXILLARY GROWTH $\left(M A X_{1}\right)$ in Evolutionary Diversity in Strigolactone Signaling Upstream of $M A X_{2}$. Plant Physiology, 161, 1885-1902. http://dx.doi.org/10.1104/pp.112.211383

[24] Cardoso, C., Zhang, Y., Jamil, M., Hepworth, J., Charnikhova, T., Dimkpa, S.O.N., Meharg, C., Wright, M.H., Liu, J., Meng, X., Wang, Y., Li, J., McCouch, S.R., Leyser, O., Price, A.H., Bouwmeester, H.J. and Ruyter-Spira, C. (2014) Natural Variation of Rice Strigolactone Biosynthesis Is Associated with the Deletion of Two MAX $X_{1}$ Orthologs. Proceedings of the National Academy of Sciences of the United States of America, 111, 2379-2384. http://dx.doi.org/10.1073/pnas.1317360111

[25] Hamiaux, C., Drummond, R.S.M., Janssen, B.J., Ledger, S.E., Cooney, J.M., Newcomb, R.D. and Snowden, K.C. (2012) DAD2 Is an $\alpha / \beta$ Hydrolase Likely to Be Involved in the Perception of the Plant Branching Hormone, Strigolactone. Current Biology, 22, 2032-2036. http://dx.doi.org/10.1016/j.cub.2012.08.007

[26] Arite, T., Umehara, M., Ishikawa, S., Hanada, A., Maekawa, M., Yamaguchi, S. and Kyozuka, J. (2009) D14, a Strigolactone-Insensitive Mutant of Rice, Shows an Accelerated Outgrowth of Tillers. Plant \& Cell Physiology, 50, 14161424. http://dx.doi.org/10.1093/pcp/pcp091

[27] Liu, W.Z., Wu, C., Fu, Y.P., Hu, G.C., Si, H.M., Zhu, L., Luan, W.J., He, Z.Q. and Sun, Z.X. (2009) Identification and Characterization of HTD2: A Novel Gene Negatively Regulating Tiller Bud Outgrowth in Rice. Planta, 230, 649-658. http://dx.doi.org/10.1007/s00425-009-0975-6

[28] Chevalier, F., Nieminen, K., Sánchez-Ferrero, J.C., Rodríguez, M.L., Chagoyen, M., Hardtke, C.S. and Cubas, P. (2014) Strigolactone Promotes Degradation of DWARF14, an $\alpha / \beta$ Hydrolase Essential for Strigolactone Signaling in Arabidopsis. The Plant Cell, 26, 1134-1150. http://dx.doi.org/10.1105/tpc.114.122903

[29] Somers, D.E. and Fujiwara, S. (2009) Thinking Outside the F-Box: Novel Ligands for Novel Receptors. Trends in Plant Science, 14, 206-213. http://dx.doi.org/10.1016/j.tplants.2009.01.003

[30] Waters, M.T., Nelson, D.C., Scaffidi, A., Flematti, G.R., Sun, Y.K., Dixon, K.W. and Smith, S.M. (2012) Specialisation within the DWARF14 Protein Family Confers Distinct Responses to Karrikins and Strigolactones in Arabidopsis. Development, 139, 1285-1295. http://dx.doi.org/10.1242/dev.074567

[31] Kretzschmar, T., Kohlen, W., Sasse, J., Borghi, L., Schlegel, M., Bachelier, J.B., Reinhardt, D., Bours, R., Bouwmeester, H.J. and Martinoia, E. (2012) A Petunia ABC Protein Controls Strigolactone-Dependent Symbiotic Signalling and Branching. Nature, 483, 341-344. http://dx.doi.org/10.1038/nature10873

[32] de Saint Germain, A., Bonhomme, S., Boyer, F.-D. and Rameau, C. (2013) Novel Insights into Strigolactone Distribution and Signalling. Current Opinion in Plant Biology, 16, 583-589. http://dx.doi.org/10.1016/j.pbi.2013.06.007

[33] Liu, Q., Zhang, Y., Matusova, R., Charnikhova, T., Amini, M., Jamil, M., Fernandez-Aparicio, M., Huang, K., Timko, M.P., Westwood, J.H., Ruyter-Spira, C., van der Krol, S. and Bouwmeester, H.J. (2014) Striga hermonthica MAX 2 Restores Branching but Not the Very Low Fluence Response in the Arabidopsis thaliana MAX 2 Mutant. New Phytologist, 202, 531-541. http://dx.doi.org/10.1111/nph.12692

[34] Westwood, J.H., dePamphilis, C.W., Das, M., Fernandez-Aparicio, M., Honaas, L.A., Timko, M.P., Wafula, E.K., Wickett, N.J. and Yoder, J.I. (2012) The Parasitic Plant Genome Project: New Tools for Understanding the Biology of Orobanche and Striga. Weed Science, 60, 295-306. http://dx.doi.org/10.1614/WS-D-11-00113.1

[35] Westwood, J.H. (2000) Characterization of the Orobanche-Arabidopsis System for Studying Parasite-Host Interactions. Weed Science, 48, 742-748. http://dx.doi.org/10.1614/0043-1745(2000)048[0742:COTOAS]2.0.CO;2

[36] Gurney, A.L., Grimanelli, D., Kanampiu, F., Hoisington, D., Scholes, J.D. and Press, M.C. (2003) Novel Sources of Resistance to Striga hermonthica in Tripsacum dactyloides, a Wild Relative of Maize. New Phytologist, 160, 557-568. http://dx.doi.org/10.1046/j.1469-8137.2003.00904.x

[37] Lynn, D.G. and Chang, M. (1990) Phenolic Signals in Cohabitation: Implications for Plant Development. Annual Review of Plant Physiology and Plant Molecular Biology, 41, 497-526. http://dx.doi.org/10.1146/annurev.pp.41.060190.002433

[38] Gurney, A.L., Slate, J., Press, M.C. and Scholes, J.D. (2006) A Novel form of Resistance in Rice to the Angiosperm Parasite Striga hermonthica. New Phytologist, 169, 199-208. http://dx.doi.org/10.1111/j.1469-8137.2005.01560.x

[39] Young, N.D. and dePamphilis, C.W. (2005) Rate Variation in Parasitic Plants: Correlated and Uncorrelated Patterns among Plastid Genes of Different Function. BMC Evolutionary Biology, 5, 16. http://dx.doi.org/10.1186/1471-2148-5-16

[40] McNeal, J.R., Bennett, J.R., Wolfe, A.D. and Mathews, S. (2013) Phylogeny and Origins of Holoparasitism in Orobanchaceae. American Journal of Botany, 100, 971-983. http://dx.doi.org/10.3732/ajb.1200448

[41] Li, L., Stoeckert Jr., C.-J. and Roos, D.-S. (2003) Orthomcl: Identification of Ortholog Groups for Eukaryotic Genomes. 
Genome Research, 13, 2178-2189. http://dx.doi.org/10.1101/gr.1224503

[42] Wall, P.K., Leebens-Mack, J., Müller, K.F., Field, D., Altman, N.S. and dePamphilis, C.W. (2008) PlantTribes: A Gene and Gene Family Resource for Comparative Genomics in Plants. Nucleic Acids Research, 36, D970-D976. http://dx.doi.org/10.1093/nar/gkm972

[43] McGinnis, S. and Madden, T.L. (2004) BLAST: At the Core of a Powerful and Diverse Set of Sequence Analysis Tools. Nucleic Acids Research, 32, W20-W25. http://dx.doi.org/10.1093/nar/gkh435

[44] Eddy, S.R. (2011) Accelerated Profile HMM Searches. PLoS Computational Biology, 7, e1002195. http://dx.doi.org/10.1371/journal.pcbi.1002195

[45] Katoh, K. and Standley, D.M. (2013) MAFFT Multiple Sequence Alignment Software Version 7: Improvements in Performance and Usability. Molecular Biology and Evolution, 30, 772-780. http://dx.doi.org/10.1093/molbev/mst010

[46] Capella-Gutiérrez, S., Silla-Martínez, J.M. and Gabaldón, T. (2009) trimAL: A Tool for Automated Alignment Trimming in Large-Scale Phylogenetic Analyses. Bioinformatics, 25, 1972-1973. http://dx.doi.org/10.1093/bioinformatics/btp348

[47] Stamatakis, A. (2006) RAxML-VI-HPC: Maximum Likelihood-Based Phylogenetic Analyses with Thousands of Taxa and Mixed Models. Bioinformatics, 22, 2688-2690. http://dx.doi.org/10.1093/bioinformatics/btl446

[48] Yang, Z. (1997) PAML: A Program Package for Phylogenetic Analysis by Maximum Likelihood. Computer Applications in the Biosciences, 13, 555-556. http://dx.doi.org/10.1093/bioinformatics/13.5.555

[49] Yang, Z. (2007) $\mathrm{PAML}_{4}$ : Phylogenetic Analysis by Maximum Likelihood. Molecular Biology and Evololution, 24, 15861591. http://dx.doi.org/10.1093/molbev/msm088

[50] González-Verdejo, C.I., Die, J.V., Nadal, S., Jiménez-Marín, A., Moreno, M.T. and Román, B. (2008) Selection of Housekeeping Genes for Normalization by Real-Time RT-PCR: Analysis of Or-MYB1 Gene Expression in Orobanche ramosa Development. Analytical Biochemistry, 379, 176-181. http://dx.doi.org/10.1016/j.ab.2008.05.003

[51] Fernández-Aparicio, M., Rubiales, D., Bandaranayake, P., Yoder, J. and Westwood, J. (2011) Transformation and Regeneration of the Holoparasitic Plant Phelipanche aegyptiaca. Plant Methods, 7, 36. http://dx.doi.org/10.1186/1746-4811-7-36

[52] Fernández-Aparicio, M., Huang, K., Wafula, E.K., Honaas, L.A., Wickett, N.J., Timko, M.P., dePamphilis, C.W., Yoder, J.I. and Westwood, J.H. (2013) Application of qRT-PCR and RNA-Seq Analysis for the Identification of Housekeeping Genes Useful for Normalization of Gene Expression Values During Striga hermonthica Development. Molecular Biology Reports, 40, 3395-3407. http://dx.doi.org/10.1007/s11033-012-2417-y

[53] Westwood, J.H. and Foy, C.L. (1999) Influence of Nitrogen on Germination and Early Development of Broomrape (Orobanche Spp.). Weed Science, 47, 2-7.

[54] Péron, T., Véronési, C., Mortreau, E., Pouvreau, J.-B., Thoiron, S., Leduc, N., Delavault, P. and Simier, P. (2012) Role of the Sucrose Synthase Encoding PrSus1 Gene in the Development of the Parasitic Plant Phelipanche ramosa L. (Pomel). Molecular Plant-Microbe Interactions, 25, 402-411. http://dx.doi.org/10.1094/MPMI-10-11-0260

[55] Nei, M. (1987) Molecular Evolutionary Genetics. Columbia University Press, New York.

[56] Messing, S.A.J., Gabelli, S.B., Echeverria, I., Vogel, J.T., Guan, J.C., Tan, B.C., Klee, H.J., McCarty, D.R. and Amzel, L.M. (2010) Structural Insights into Maize Viviparous14, a Key Enzyme in the Biosynthesis of the Phytohormone Abscisic Acid. The Plant Cell, 22, 2970-2980. http://dx.doi.org/10.1105/tpc.110.074815

[57] van den Brule, S. and Smart, C.C. (2002) The Plant PDR Family of ABC Transporters. Planta, 216, 95-106. http://dx.doi.org/10.1007/s00425-002-0889-z

[58] Dun, E.A., Brewer, P.B. and Beveridge, C.A. (2009) Strigolactones: Discovery of the Elusive Shoot Branching Hormone. Trends in Plant Science, 14, 364-372. http://dx.doi.org/10.1016/j.tplants.2009.04.003

[59] Johnson, X., Brcich, T., Dun, E.A., Goussot, M., Haurogné, K., Beveridge, C.A. and Rameau, C. (2006) Branching Genes Are Conserved across Species. Genes Controlling a Novel Signal in Pea Are Coregulated by Other Long-Distance Signals. Plant Physiology, 142, 1014-1026. http://dx.doi.org/10.1104/pp.106.087676

[60] Dun, E.A., de Saint Germain, A., Rameau, C. and Beveridge, C.A. (2013) Dynamics of Strigolactone Function and Shoot Branching Responses in Pisum sativum. Molecular Plant, 6, 128-140. http://dx.doi.org/10.1093/mp/sss131

[61] Evidente, A., Fernandez-Aparicio, M., Cimmino, A., Rubiales, D., Andolfi, A. and Motta, A. (2009) Peagol and Peagoldione, Two New Strigolactone-Like Metabolites Isolated from Pea Root Exudates. Tetrahedron Letters, 50, 69556958. http://dx.doi.org/10.1016/j.tetlet.2009.09.142

[62] Evidente, A., Cimmino, A., Fernández-Aparicio, M., Rubiales, D., Andolfi, A. and Melck, D. (2011) Soyasapogenol B and Trans-22-Dehydrocam-Pesterol from Common Vetch (Vicia sativa L.) Root Exudates Stimulate Broomrape Seed Germination. Pest Management Science, 67, 1015-1022. http://dx.doi.org/10.1002/ps.2153

[63] Evidente, A., Cimmino, A., Fernandez-Aparicio, M., Andolfi, A., Rubiales, D. and Motta, A. (2010) Polyphenols, In- 
cluding the New Peapolyphenols A-C, from Pea Root Exudates Stimulate Orobanche foetida Seed Germination. Journal of Agricultural and Food Chemistry, 58, 2902-2907. http://dx.doi.org/10.1021/jf904247k

[64] Yoneyama, K., Yoneyama, K., Takeuchi, Y. and Sekimoto, H. (2007) Phosphorus Deficiency in Red Clover Promotes Exudation of Orobanchol, the Signal for Mycorrhizal Symbionts and Germination Stimulant for Root Parasites. Planta, 225, 1031-1038. http://dx.doi.org/10.1007/s00425-006-0410-1

[65] Harrison, M.J. (2005) Signaling in the Arbuscular Mycorrhizal Symbiosis. Annual Review of Microbiology, 59, 19-42. http://dx.doi.org/10.1146/annurev.micro.58.030603.123749

[66] Gomez-Roldan, V., Fermas, S., Brewer, P.B., Puech-Pages, V., Dun, E.A., Pillot, J.-P., Letisse, F., Matusova, R., Danoun, S., Portais, J.-C., Bouwmeester, H., Becard, G., Beveridge, C.A., Rameau, C. and Rochange, S.F. (2008) Strigolactone Inhibition of Shoot Branching. Nature, 455, 189-194. http://dx.doi.org/10.1038/nature07271

[67] Umehara, M., Hanada, A., Yoshida, S., Akiyama, K., Arite, T., Takeda-Kamiya, N., Magome, H., Kamiya, Y., Shirasu, K., Yoneyama, K., Kyozuka, J. and Yamaguchi, S. (2008) Inhibition of Shoot Branching by New Terpenoid Plant Hormones. Nature, 455, 195-200. http://dx.doi.org/10.1038/nature07272

[68] Leyser, O. (2009) The Control of Shoot Branching: An Example of Plant Information Processing. Plant, Cell \& Environment, 32, 694-703. http://dx.doi.org/10.1111/j.1365-3040.2009.01930.x

[69] Kohlen, W., Charnikhova, T., Liu, Q., Bours, R., Domagalska, M.A., Beguerie, S., Verstappen, F., Leyser, O., Bouwmeester, H. and Ruyter-Spira, C. (2011) Strigolactones Are Transported through the Xylem and Play a Key Role in Shoot Architectural Response to Phosphate Deficiency in Nonarbuscular Mycorrhizal Host Arabidopsis. Plant Physiology, 155, 974-987. http://dx.doi.org/10.1104/pp.110.164640

[70] Irving, L.J. and Cameron, D.D. (2009) Chapter 3 You Are What You Eat: Interactions between Root Parasitic Plants and Their Hosts. Advances in Botanical Research, 50, 87-138. http://dx.doi.org/10.1016/S0065-2296(08)00803-3

[71] dePamphilis, C. and Palmer, J. (1990) Loss of Photosynthetic and Chlororespiratory Genes from the Plastid Genome of a Parasitic Flowering Plant. Nature, 348, 337-339. http://dx.doi.org/10.1038/348337a0

[72] Wickett, N.J., Honaas, L.A., Wafula, E.K., Das, M., Huang, K., Wu, B., Landherr, L., Timko, M.P., Yoder, J., Westwood, J.H. and dePamphilis, C.W. (2011) Transcriptomes of the Parasitic Plant Family Orobanchaceae Reveal Surprising Conservation of Chlorophyll Synthesis. Current Biology, 21, 2098-2104. http://dx.doi.org/10.1016/j.cub.2011.11.011

[73] Plakhine, D., Tadmor, Y., Ziadne, H. and Joel, D.M. (2012) Maternal Tissue Is Involved in Stimulant Reception by Seeds of the Parasitic Plant Orobanche. Annals of Botany, 109, 979-986. http://dx.doi.org/10.1093/aob/mcs016

[74] Yoneyama, K., Xie, X., Sekimoto, H., Takeuchi, Y., Ogasawara, S., Akiyama, K., Hayashi, H. and Yoneyama, K. (2008) Strigolactones, Host Recognition Signals for Root Parasitic Plants and Arbuscular Mycorrhizal Fungi, from Fabaceae Plants. New Phytologist, 179, 484-494. http://dx.doi.org/10.1111/j.1469-8137.2008.02462.x

[75] Yoneyama, K., Ruyter-Spira, C. and Bouwmeester, H. (2013) Induction of Germination. In: Joel, D.M., Gressel, J. and Musselman, L.J., Ed., Parasitic Orobanchaceae, Springer, Berlin Heidelberg, 167-194. http://dx.doi.org/10.1007/978-3-642-38146-1_10

[76] Fernandez-Aparicio, M., Flores, F. and Rubiales, D. (2009) Recognition of Root Exudates by Seeds of Broomrape (Orobanche and Phelipanche) Species. Annals of Botany, 103, 423-431. http://dx.doi.org/10.1093/aob/mcn236

[77] Fernández-Aparicio, M., Pérez-de-Luque, A., Prats, E. and Rubiales, D. (2008) Variability of Interactions between Barrel Medic (Medicago truncatula) Genotypes and Orobanche Species. Annals of Applied Biology, 153, 117-126. http://dx.doi.org/10.1111/j.1744-7348.2008.00241.x 